\title{
Cetuximab-resistant oral squamous cell carcinoma cells become sensitive in anchorage-independent culture conditions through the activation of the EGFR/AKT pathway
}

\author{
YUICHI OHNISHI $^{1,2}$, HIROKI YASUI ${ }^{1,2}$, KENJI KAKUDO ${ }^{2}$ and MASAMI NOZAKI ${ }^{1}$ \\ ${ }^{1}$ Department of Cell Biology, Research Institute for Microbial Diseases, Osaka University, Suita, Osaka 565-0871; \\ ${ }^{2}$ Second Department of Oral and Maxillofacial Surgery, Osaka Dental University, Hirakata, Osaka 573-1121, Japan
}

Received September 2, 2015; Accepted September 26, 2015

DOI: $10.3892 /$ ijo.2015.3215

\begin{abstract}
We have previously shown that growth of the oral squamous cell carcinoma cell line SAS, is resistant to cetuximab in monolayer culture conditions, even though epidermal growth factor receptor (EGFR) was phosphorylated, but the growth of SAS aggregates was sensitive to cetuximab. In the present study, we demonstrate differences in the EGFR signaling pathways utilized by SAS cells in monolayer and suspension cultures at the molecular level. Cetuximab treatment of SAS cells in monolayer cultures inhibits the phosphorylation of EGFR and ERK, and reduces the cell migratory potency, but not cell proliferation. AG1478 treatment reduces the phosphorylation of EGFR, ERK and AKT, and affects cell growth in monolayer cultures. The phosphorylation levels of EGFR and AKT are significantly higher in SAS cell aggregates compared to monolayer cultures. Treatment with cetuximab and AG1478 reduces the growth of SAS aggregates and eliminates the phosphorylation of EGFR and AKT. Furthermore, proliferation of SAS aggregates is also inhibited by LY294002 and MK2206, which are inhibitors of PI3K and AKT, respectively. In addition, treatment with the lipid raft disruptor filipin III reduced the phosphorylation levels of EGFR and Akt in SAS aggregates, but not in SAS monolayer culture. These results suggest the possibility that ligands in the serum stimulate the phosphorylation of EGFR localized in lipid rafts leading to PI3K-AKT activation, which results in the growth of SAS aggregates, therefore resulting in the sensitivity of SAS aggregates to cetuximab.
\end{abstract}

Correspondence to: Dr Masami Nozaki, Department of Cell Biology, Research Institute for Microbial Diseases, Osaka University, 3-1 Yamadaoka, Suita, Osaka 565-0871, Japan

E-mail: mnozaki@biken.osaka-u.ac.jp

Abbreviations: EGFR, epidermal growth factor receptor; OSCC, oral squamous cell carcinoma; DMEM, Dulbeco's modified Eagle's medium; FBS, fetal bovine serum

Key words: epidermal growth factor receptor, cetuximab, aggregation culture, cell growth, cell migration

\section{Introduction}

Head-and-neck squamous cell carcinoma (HNSCC) is the most common cancer in the head and neck region, and affects $\sim 550,000$ patients worldwide (1). The overall 5-year survival rate of HNSCC including oral squamous cell carcinoma (OSCC) is $\sim 50 \%$, which has not improved markedly during the last decade $(2,3)$. Thus, new effective therapeutic modalities are needed to improve survival of HNSCC patients.

The epidermal growth factor receptor (EGFR) is a member of the receptor tyrosine kinase (TK) or HER family, which consists of EGFR (HER1/ErbB1), HER2/Neu (ErbB2), HER3 (ErbB3), and HER4 (ErbB4). Stimulation of the receptors through ligand binding activates the receptor tyrosine kinase and promotes its homodimerization or heterodimerization with another HER. EGFR activation stimulates a number of downstream signaling cascades, such as the RAS/RAF/ERK/ MAPK, phosphatidylinositol 3-kinase (PI3K)/AKT pathway, and the phospholipase C- $\gamma /$ protein kinase C (PLC $\gamma / \mathrm{PKC})$ pathway, and including the Src family kinases (SFKs), and the signal transducers and activators of transcription (STATs). These pathways affect various cellular responses, including proliferation, survival, migration, angiogenesis and metastasis (4-10).

EGFR is constitutively distributed in normal epithelial cells, but it is highly expressed in various cancers, including those of the breast, prostate, and lung cancers, as well as gliomas (11). EGFR is expressed at higher levels in $>95 \%$ of HNSCCs compared to normal mucosa (12). Furthermore, upregulation of EGFR expression in HNSCC has been reported to be associated with an unfavorable prognosis and is a useful prognostic biomarker of low survival rate $(13,14)$. Therefore, EGFR is considered to be one of the most promising molecular targets in oncology, and EGFR-targeted therapies have been developed using monoclonal antibodies (mAbs) to the extracellular ligand-binding domain of the EGFR.

Cetuximab is a chimeric $\mathrm{mAb}$ consisting of a $\mathrm{Fv}$ region of mouse anti EGFR antibody and human IgG1 heavy and $\kappa$ lightchain constant regions, which binds with high affinity to the extracellular domain of EGFR (15) and subsequently blocks EGFR activation by preventing TK-mediated phosphorylation of the protein (16). As a result, cetuximab promotes apoptosis, 
and inhibits cell cycle progression, tumor cell invasion and angiogenesis.

Cetuximab has already been used in the clinic, however, intrinsic or acquired resistance to EGFR therapy remains a major obstacle to achieving positive clinical outcomes with cetuximab $(17,18)$. In order to resolve these problems, it is important to understand both the mechanisms of action and resistance to cetuximab.

The OSCC cell line SAS, exhibits proliferation that is not sensitive to cetuximab treatment, although SAS cells do express EGFR and also undergo phosphorylation. However, SAS growth has been reported to be inhibited by cetuximab under aggregation culture conditions (19). In this study, we investigated the molecular basis of changes in cetuximab sensitivity facilitated by growth signals provided by culture conditions in SAS cells.

\section{Materials and methods}

Cell culture and reagents. Three OSCC cell lines, HSC3, HSC4, and SAS, were purchased from RIKEN Bioresource Center (Ibaraki, Japan). Cells were cultured in Dulbecco's modified Eagle's medium (DMEM) supplemented with $10 \%(\mathrm{v} / \mathrm{v})$ fetal bovine serum (FBS) at $37^{\circ} \mathrm{C}$ in a humidified atmosphere of $5 \% \mathrm{CO}_{2}$. DMEM and FBS were purchased from Gibco (Life Technologies, Tokyo, Japan). Antibodies used included anti-EGFR (Cell Signaling Technology, Tokyo, Japan), anti-phospho-EGFR (Tyr1068, Cell Signaling Technology), anti-ERK1 (Santa Cruz Biotechnology, CA, USA), anti-phospho-ERK (Santa Cruz Biotechnology), anti-AKT (Cell Signaling Technology), anti-phospho-AKT (Ser473, Cell Signaling Technology), anti-caveolin-1 (Santa Cruz Biotechnology), anti-phospho-caveolin-1 (Tyr14, Cell Signaling Technology), and anti- $\alpha$-tubulin (Sigma-Aldrich, Tokyo, Japan). Cetuximab (Erbitux ${ }^{\circledR}$ ) was purchased from Merck Serono (Tokyo, Japan). AG1478, TAPI-2, LY294002 and MK2206 were from Calbiochem (Merk Millipore, Tokyo, Japan).

Cell proliferation assay. Human OSCC cells ( $2 \times 10^{3} /$ well) were plated in 96-well plates. After $24 \mathrm{~h}$ of growth, various reagents were added at the indicated concentrations and growth continued for an additional 2, 4, or 6 days. All experiments were performed in triplicate. Cell proliferation was assessed using the CellTiter $96^{\circledR}$ Non-Radioactive Cell Proliferation assay (Promega, Tokyo, Japan).

Aggregation cultures. When aggregation culture conditions were utilized, $1-5 \times 10^{3}$ cells were seeded into each well of lowadhesive 96-well plates (Sumitomo Bakelite, Tokyo, Japan) and cultured in DMEM supplemented with $10 \%$ (v/v) FBS at $37^{\circ} \mathrm{C}$ under $5 \% \mathrm{CO}_{2}$.

Western blotting. Cells were washed with phosphate-buffered saline (PBS) and then lysed with RIPA buffer consisting of $150 \mathrm{mM} \mathrm{NaCl}, 10 \mathrm{mM}$ Tris-HCl, $\mathrm{pH} 8.0,1 \%$ (V/V) Nonidate P-40, $0.5 \%$ (W/V) deoxycholic acid, $0.1 \%$ (W/V) SDS, 5 mM EDTA, 1X Halt ${ }^{\mathrm{TM}}$ protease inhibitor cocktail (Thermo Fisher Scientific, Yokohama, Japan), and 1X Halt ${ }^{\mathrm{TM}}$ Protein phosphatase inhibitor (Thermo Fisher Scientific). The protein concentration of the lysates was determined using a $\mathrm{BCA}^{\mathrm{TM}}$ Protein assay kit (Thermo Fisher Scientific) and equal amounts of protein were subjected to SDS-polyacrylamide gel electrophoresis. The separated proteins were electrophoretically transferred onto PVDF membranes (GE Healthcare, $\mathrm{UK})$. Non-specific binding was blocked by incubation in $5 \%(\mathrm{~W} / \mathrm{V})$ bovine serum albumin (BSA) in TBS/Tween-20 (TBS-T) for $1 \mathrm{~h}$ at room temperature. Membranes were probed with antibodies in TBS-T overnight at $4^{\circ} \mathrm{C}$ and then incubated with HRP-conjugated secondary antibody. Antibody-antigen complexes were detected by ECL plus western blotting detection reagent (GE Healthcare).

Scratch wound healing assay. Cell migration was determined by a scratch wound healing assay as described (20), with slight modifications. Briefly, cells at a semi-confluence in 12 -well plates were treated with $10 \mu \mathrm{g} / \mathrm{ml}$ of mitomycin $\mathrm{C}$ for $4 \mathrm{~h}$ to block proliferation and subsequently wounded with a sterile $200-\mu$ l pipette tip to generate a cell-free gap $\sim 1 \mathrm{~mm}$ in width. Cells were then washed with PBS and photographed to record the wound width at $0 \mathrm{~h}$. Next, one group of cells was cultured in DMEM with $10 \%$ FBS for $24 \mathrm{~h}$ as a control. Other groups were treated with various concentrations of cetuximab. Twenty-four hours later, photographs were taken to evaluate migration.

Immunofluorescence staining. Cultured cells were fixed in $3.5 \%$ $(\mathrm{w} / \mathrm{v})$ formaldehyde, permeabilized in $0.2 \%$ (v/v) Triton X-100, and blocked in $2 \%(\mathrm{w} / \mathrm{v}) \mathrm{BSA}$. The primary antibodies were incubated at $4^{\circ} \mathrm{C}$ overnight. Alexa fluor 488-conjugated IgG (Life Technologies) was used as the secondary antibody. After incubation with the antibodies, SlowFade Gold Antifade reagent with 4',6-diamidino-2-phenylindole (DAPI; Invitrogen/Life Technologies) was added. The specimens were observed using fluorescence microscopy.

\section{Results}

Cetuximab inhibits EGFR phosphorylation, resulting in reduced cell migratory activity, but not growth, of $S A S$, an OSCC cell line. We previously reported that SAS cell growth is poorly sensitive to cetuximab or AG1478 treatment in a monolayer culture, even though EGFR is expressed and phosphorylated (19), indicating that EGFR phosphorylation is minimally involved in SAS cell proliferation.

To evaluate the concentration and time-dependency of cetuximab or AG1478 on oral squamous cell carcinoma (OSCC) cell proliferation, we exposed HSC3, HSC4, and SAS cells to various concentrations of cetuximab or AG1478 for 2-6 days and measured cell activity by MTT assays. The growth rate of SAS cells was not affected by each concentration of cetuximab in 6 days of culture; however, proliferation of HSC3 and HSC4 cells were reduced after 2-4 days in culture (Fig. 1A). Proliferation of HSC3 and HSC4 cells ceased after 2 days in culture in the presence of $>5 \mu \mathrm{M}$ AG1478; however, growth of SAS cells was maintained until day 4 of culture and then inhibited after 6 days in $10 \mu \mathrm{M}$ AG1478 (Fig. 1A).

Next, we examined whether cetuximab inhibits phosphorylation of EGFR in SAS monolayer cultures by performing western blotting using an anti-phospho-EGFR antibody. 
A

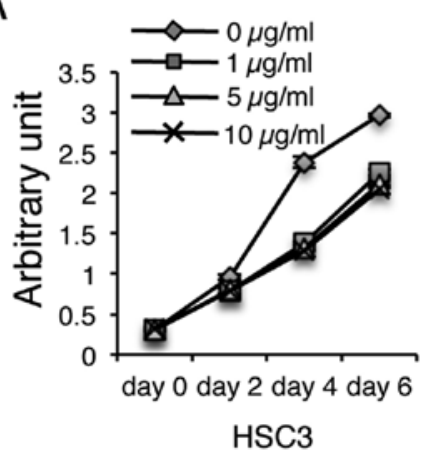

cetuximab

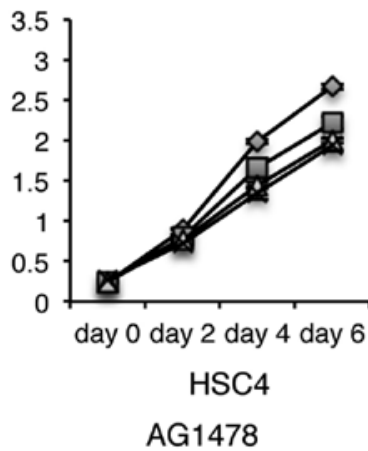

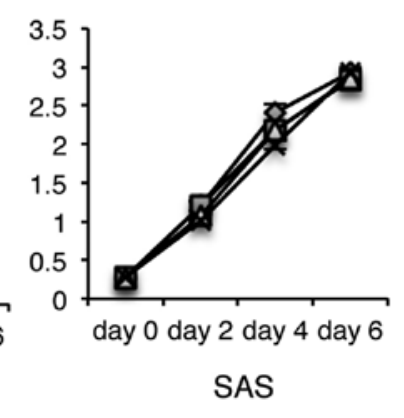

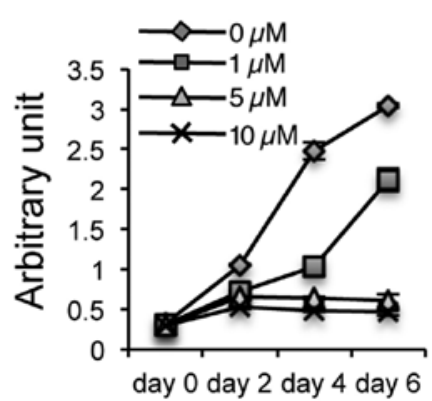

HSC3

B

Cetuximab

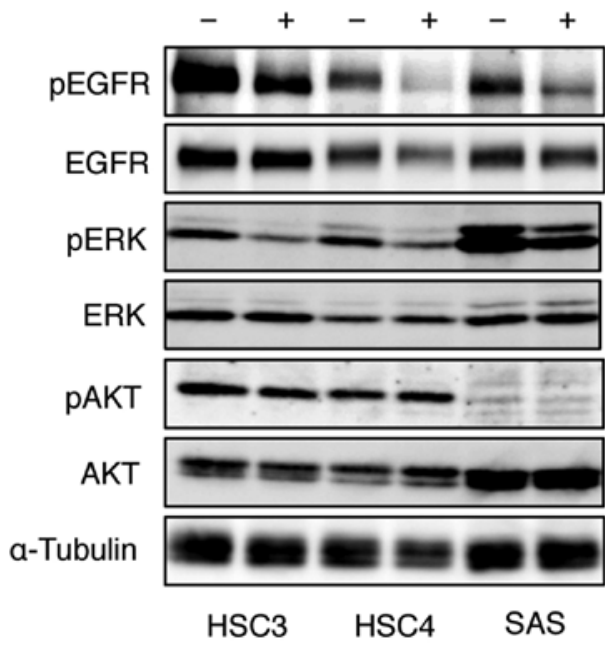

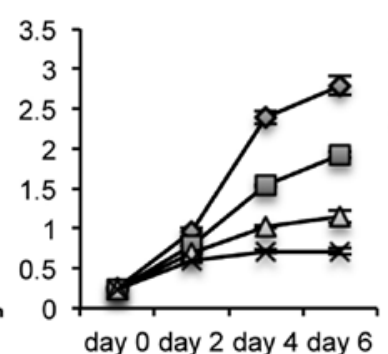

HSC4

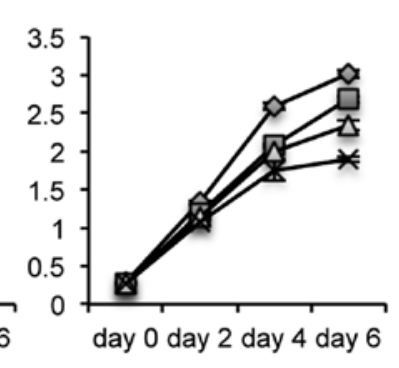

SAS

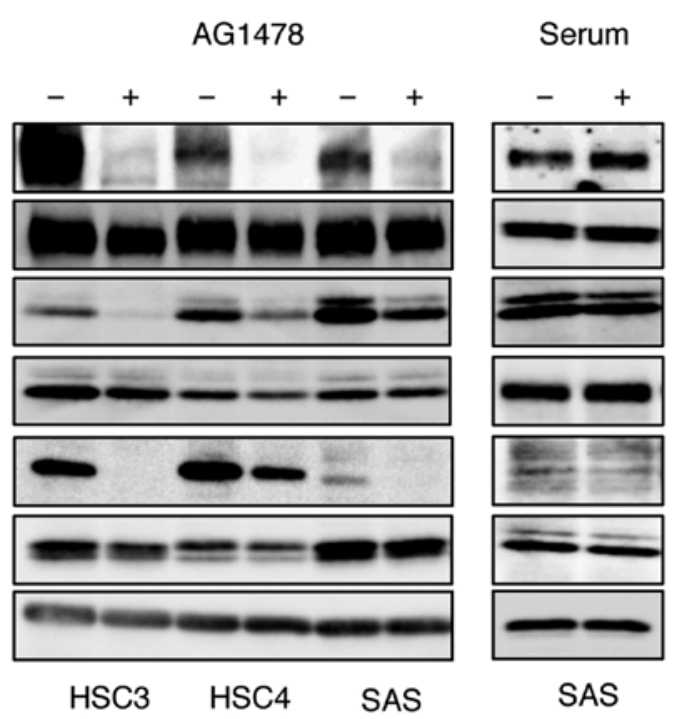

Figure 1. Cetuximab reduces the phosphorylation levels of EGFR, but does not affect the growth of SAS cells. (A) Each cell line was cultured in cetuximab or AG1478 at the indicated concentration. MTT activity was measured on each day of culture. (B) Cells were treated with cetuximab, AG1478, or serum and the phosphorylation levels of EGFR, ERK, and AKT were determined by immunoblotting for EGFR, pEGFR Y1068, ERK, pERK Y209, AKT and pAkt S473, respectively. $\alpha$-tubulin was used as loading control.

Cetuximab treatment clearly reduced the phosphorylation level of EGFR, although the inhibition by cetuximab was less effective than that observed by AG1478 (Fig. 1B). AG1478 treatment almost eliminated EGFR phosphorylation in all cells examined (Fig. 1B). Furthermore, EGFR phosphorylation levels were increased by serum stimulation (Fig. 1B), although SAS cells actively proliferate in serum-free culture conditions as described previously (19). These results indicate that the inhibitory effects of cetuximab on EGFR phosphorylation are weaker than those of AG1478, and EGFR phosphorylation signals are not the main factor inducing proliferation of SAS cells in monolayer cultures.
To investigate the effects of cetuximab treatment on downstream EGFR signaling events, western blotting was performed using anti-phospho-ERK and -AKT antibodies. ERK and AKT protein levels were not altered in any of the tested cell lines following cetuximab treatment. However, phosphorylated ERK levels were reduced in all cells, but phosphorylated AKT levels were unchanged (Fig. 1B), even though phosphorylated AKT was faintly detected in SAS cells. In response to AG1478 treatment, ERK phosphorylation levels were further reduced compared to cetuximab treatment, and AKT phosphorylation levels were markedly suppressed by AG1478 treatment. These results suggest that cetuximab and 

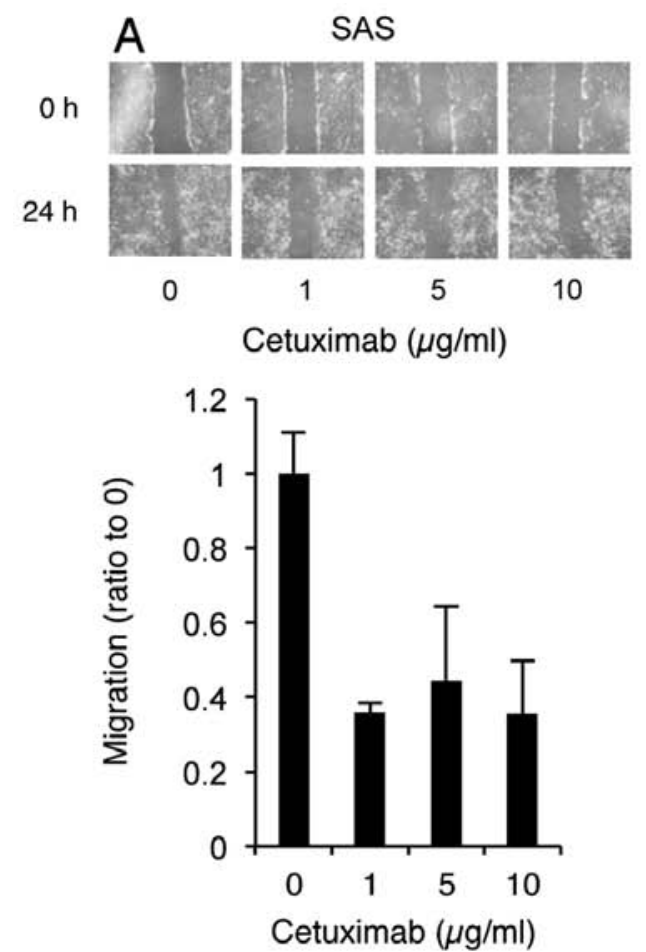

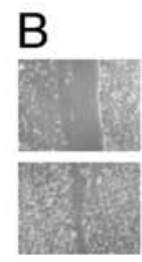

0

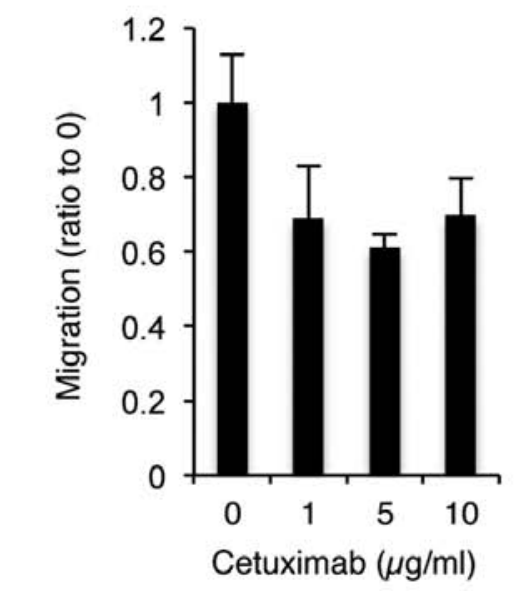

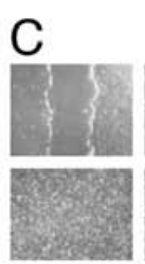

0

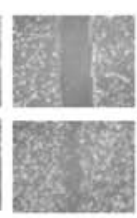

$\begin{array}{cc}1 & 5 \\ \text { Cetuximab }(\mu \mathrm{g} / \mathrm{ml})\end{array}$$$
\text { . }
$$

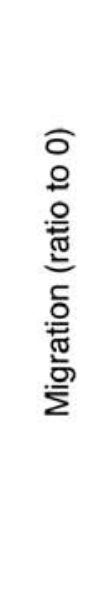

Figure 2. Cetuximab inhibits SAS cell migration. Scratch wound healing assays were performed to compare the migration capability of SAS (A), HSC3 (B), and HSC4 (C) cells in the presence or absence of cetuximab treatment. The width of the scratches were measured at $0 \mathrm{~h}$ and after $24 \mathrm{~h}$ of culture using Image J software. The relative distance was calculated as the mean width of the cell scratch. The effect of cetuximab treatment on cell migration was investigated by comparing the width of treated and non-treated cells; the non-treated width was set at 1.0.

AG1478 treatments exert different inhibitory effects on EGFR signaling. Inhibition of EGFR phosphorylation by cetuximab affects the ERK pathway, while AG1478-induced inhibition of EGFR phosphorylation affects both the ERK and AKT pathways.

In addition to cell proliferation, EGFR signaling impacts other important physiological properties, including migration, differentiation, and apoptosis $(21,22)$. To determine if cell migration was inhibited in response to the cetuximab-induced reduction in EGFR phosphorylation, a wound healing assay in the presence of cetuximab was performed. Cultured cells that formed a confluent sheet were treated with mitomycin $\mathrm{C}$, and scratched with a plastic tip. After 24-h culture, the distance of migration of non-treated and treated cells was measured. Cetuximab treatment markedly inhibited the migratory activity of SAS cells (Fig. 2A). Inhibitory effects of cetuximab were moderate in HSC3 cells, and almost absent in HSC4 cells (Figs. 2B and C). These results suggest that alterations in EGFR signaling induced by cetuximab play an important role in SAS cell migration.

Growth of SAS aggregates is induced by EGFR signaling through serum stimulation and cetuximab sensitivity. SAS cell growth was actively maintained in serum-free culture conditions (19). In order to determine whether the serumindependent growth of SAS cells is induced by autocrine/ paracrine regulation, the effects of the sheddase inhibitor TAPI-2 on SAS cell proliferation were examined. HSC4 cells, which proliferate weakly in serum-free culture conditions, ceased to undergo proliferation in response to TAPI-2 treat- ment, but SAS cell growth was maintained throughout 6 days of culture with TAPI-2 (Fig. 3A), indicating that the serumindependent growth of SAS cells is not induced through the release of factors by ADAM17, as observed in HSC4. These data suggest that SAS cell growth in monolayer culture conditions is independent of ligand stimulation.

SAS cells become aggregates in floating culture in lowadhesive U-shaped 96-well plates. Growth of SAS aggregates ceased in serum-free culture conditions, and when treated with cetuximab or AG1478 treatment (Fig. 3B), consistent with a previous report (19). These data indicate that EGFR stimulation is involved in the growth of SAS aggregates. To investigate the level of EGFR phosphorylation in aggregates treated with cetuximab, we performed western blotting using phospho-EGFR specific antibodies. Phosphorylation levels of EGFR were increased in aggregates compared to cells cultured in a monolayer and were slightly upregulated by the addition of serum (Fig. 3C). Furthermore, cetuximab treatment of SAS aggregates almost inhibited the EGFR phosphorylation (Fig. 3C). These results suggest that EGFR phosphorylation of SAS aggregates is induced in response to serum stimulation, and facilitates the transition of SAS aggregate growth to become sensitive to cetuximab.

Cetuximab sensitivity of SAS aggregate growth is EGFR$P I 3 K-A K T$ pathway-dependent. Signaling through the EGFR is transmitted to the nucleus through various routes. In the present study, we investigated the involvement of the MAPK/ERK and the PI3K-AKT pathways downstream of EGFR activation in SAS aggregates. ERK is phosphorylated 
A
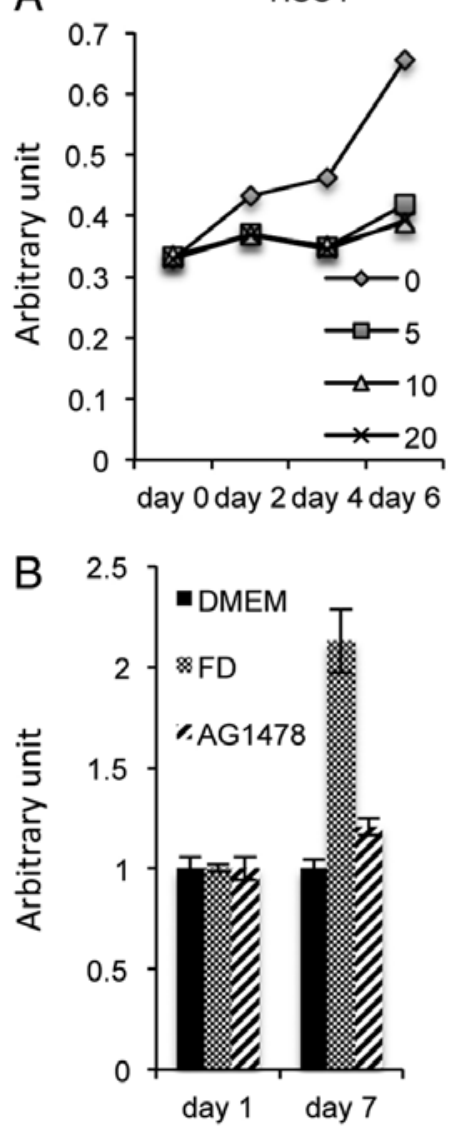

SAS
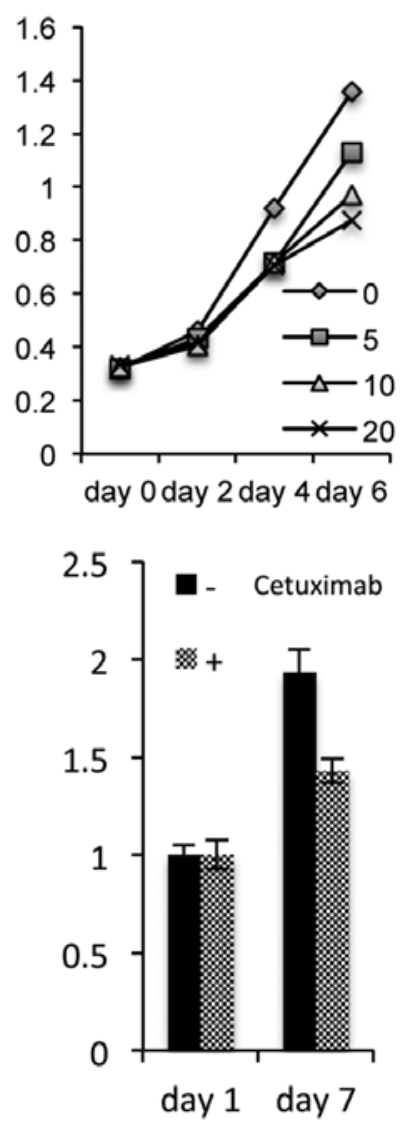

C

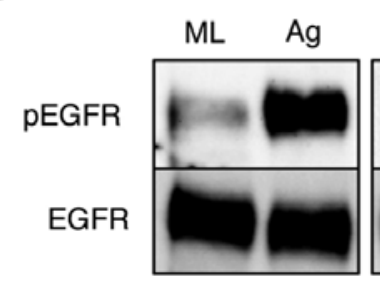

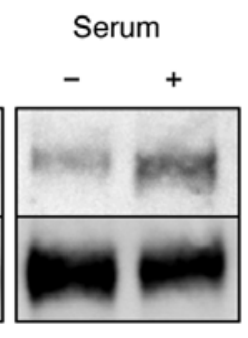

$\mathrm{Ag}$

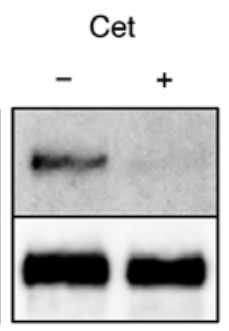

$\mathrm{Ag}$

Figure 3. Growth of SAS aggregates is regulated by serum stimulation through EGFR activation. (A) HSC4 and SAS cells were cultured in 96-well tissue culture plates in DMEM with TAPI-2 $(0,5,10$ and $20 \mu \mathrm{M})$ for 2 , 4, or 6 days. MTT activities were measured at each time-point. (B) SAS aggregates were cultured in low-adhesive 96-well plates in DMEM with (FD) or without $10 \%$ FBS (DMEM), AG1478, or cetuximab. The diameter of the aggregates was measured at days 1 and 7 of culture. Growth of the aggregates was determined by comparing the diameter of day-7 aggregates to day-1 aggregates; the day 1 value was set at 1. (C) EGFR phosphorylation levels in SAS aggregates were determined by western blotting, samples were extracted from SAS cells grown in monolayer (ML) or aggregates (Ag). SAS aggregates in DMEM with (+) or without (-) serum, and SAS aggregates in 10 FCS-DMEM with (+) or without (-) cetuximab (cet).

in SAS monolayer cultures, whereas, AKT is weakly phosphorylated (Fig. 4A). The phosphorylation of Akt increased, but the phosphorylation of ERK decreased in SAS aggregates (Fig. 4A) compared to monolayer cultures. Moreover, AKT phosphorylation was suppressed by cetuximab treatment in aggregates, and the phosphorylation of ERK was not affected by cetuximab treatment in aggregates (Fig. 4A). These results indicate that AKT phosphorylation in SAS aggregates was suppressed by the inhibition of EGFR phosphorylation.

A

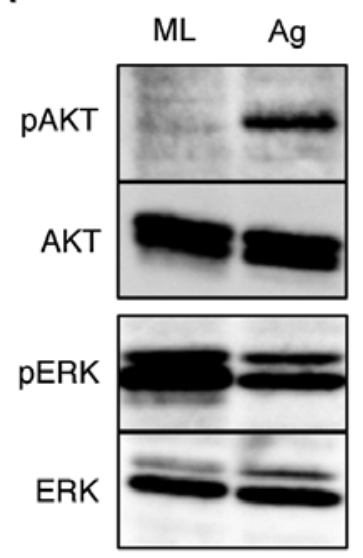

B

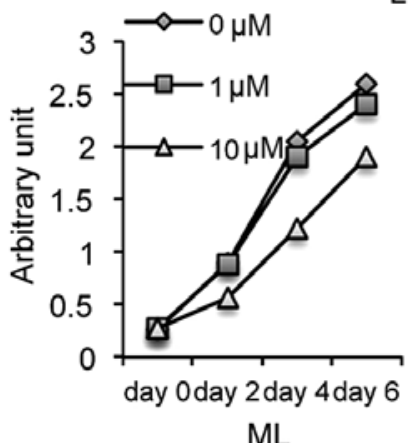

LY

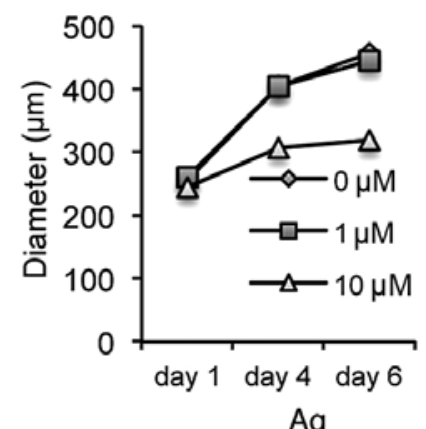

MK

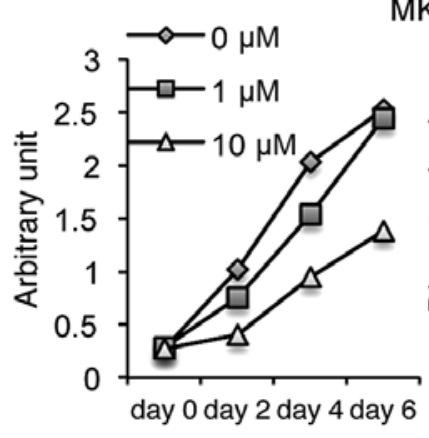

ML

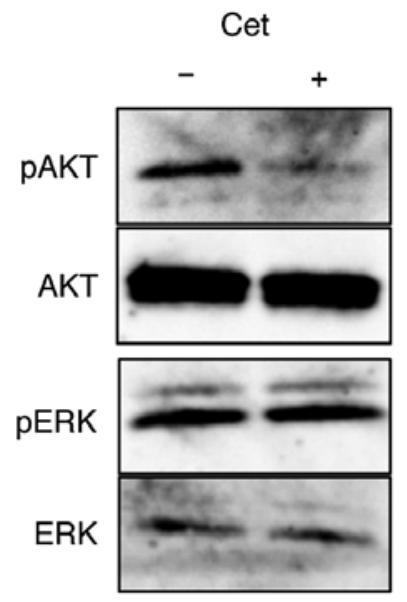

$\mathrm{Ag}$

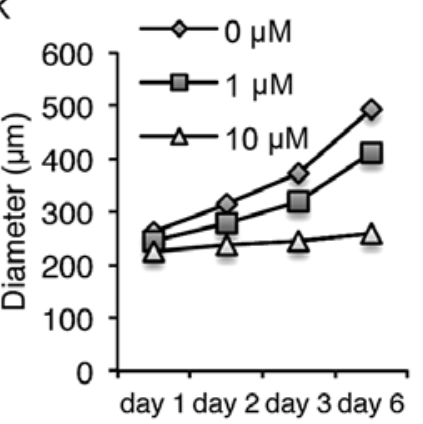

$\mathrm{Ag}$
Figure 4. Growth of SAS aggregates was regulated by AKT activation. (A) Phosphorylation levels of Akt and ERK in SAS cells grown in monolayer (ML) or aggregates (Ag), and cetuximab (cet)-treated SAS aggregates were determined by western blotting. (B) Monolayer cultures of SAS cells (ML) were treated with LY294002 (LY) or MK2206 (MK) for 0-6 days and MTT activity was measured at each time-point. SAS aggregates (Ag) were treated with LY and MK for 0-6 days and the aggregate diameter was measured at each time-point.

To assess whether the PI3K-AKT pathway is required for the growth of SAS aggregates, the effect of the PI3K inhibitor LY294002 or the AKT inhibitor MK2206 on SAS aggregate proliferation was investigated. Proliferation of SAS cells was not inhibited by either agent at $10 \mu \mathrm{M}$ in a monolayer culture (Fig. 4B). However, proliferation of SAS aggregates nearly ceased following addition of $10 \mu \mathrm{M}$ of both inhibitors (Fig. 4B). These results suggest that the EGFR-PI3K-AKT pathway plays a cruicial role in SAS growth under anchorage-independent conditions. 
A

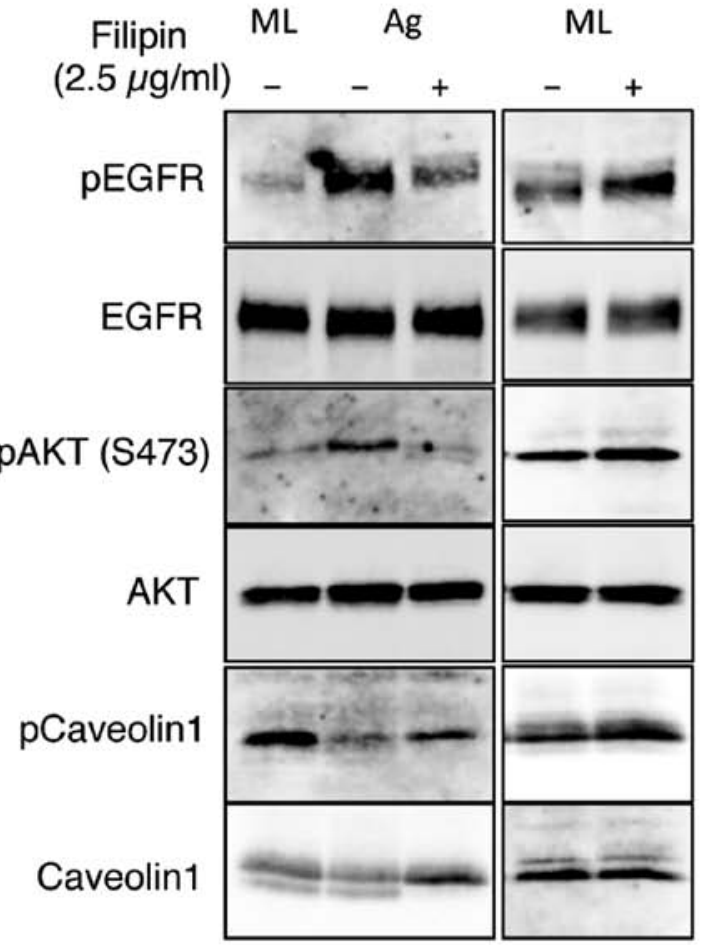

B

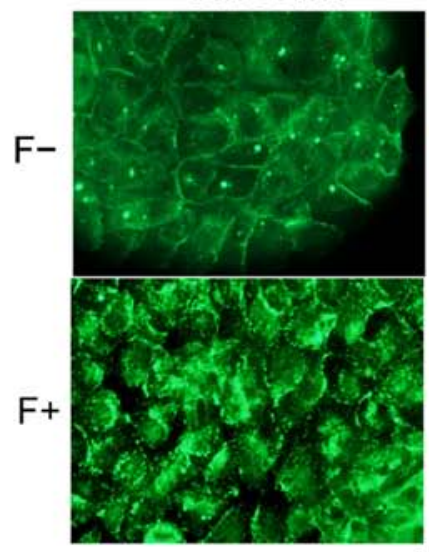

$\mathrm{ML}$

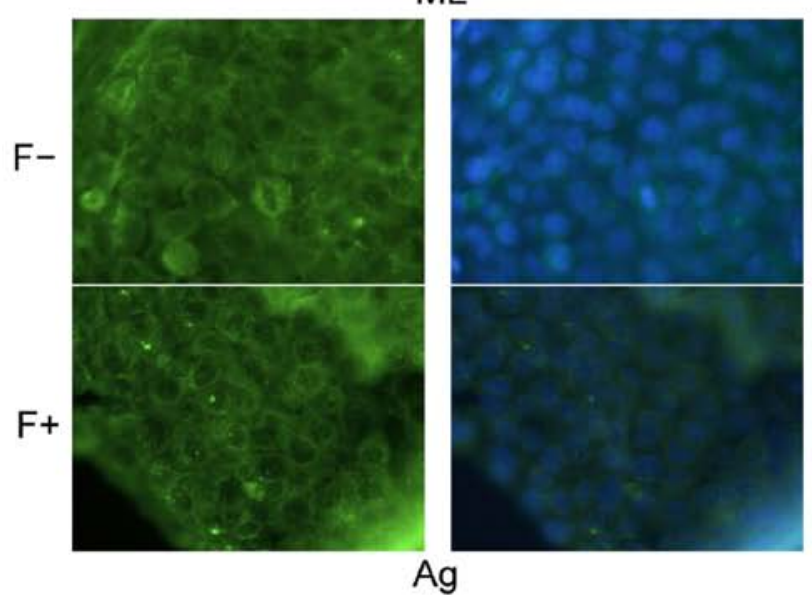

Figure 5. Filipin III reduced the phosphorylation levels of EGFR and Akt, but did not affect the cytoplasmic distribution of cavl in SAS aggregates. (A) SAS aggregates (Ag) and monolayer cultures (ML) were treated with filipin III $(2.5 \mu \mathrm{g} / \mathrm{ml})$. Phosphorylation levels of EGFR, Akt, and cav1 were determined by western blotting. (B) Monolayer cultures (upper panel) and aggregates (lower panel) of SAS cells with (F+) or without (F-) filipin III were immunostained for cav1. Nuclei were stained with DAPI.
EGFR is stimulated in lipid rafts in SAS aggregates. The finding that phosphorylation of EGFR and AKT was upregulated by aggregation in floating cultures of SAS cells indicates that distinct EGFR signaling pathways are used in different culture conditions. EGFR is localized mainly at the plasma membrane and is activated by signals from the environment. The plasma membrane contains discrete heterogeneous microdomains (23), including lipid rafts that act as platforms for cellular signaling (24). EGFR has been reported to be localized in the lipid rafts (25). To explore whether lipid rafts may also provide such a platform of EGFR phosphorylation in SAS aggregates, we sought to assess the effects of lipid raft disruption. We used the filipin III, which preferentially removes cholesterol from plasma membranes, to perturb the lipid rafts (26-28). Filipin III treatment inhibited the phophorylation of EGFR and AKT in SAS aggregates, but not in monolayer cultures (Fig. 5A), indicating that lipid rafts are involved in EGFR transactivation in SAS aggregates.

A previous report showed that caveolin-1 (cav1) phosphorylation is required for EGFR and AKT activation in a specific environment (29). Thus, we next examined cavl expression and its phosphorylation in SAS aggregates. Cav1 was detected in equal amounts in both SAS cell aggregates and in monolayers. However, its phosphorylation levels were only downregulated in aggregates (Fig. 5A). Immunocytological staining demonstrated that in SAS monolayer cultures, cavl was localized on the cell surface and transloated into the cytoplasm in response to filipin III treatment (Fig. 5B, ML). However, cav1 was localized in the cytoplasm in SAS aggregates and its localization was not affected by filipin III treatment (Fig. 5B, Ag). These results indicate that in SAS aggregates, non-phosphorylated cav1 was localized in the cytoplasm and not involved with lipid rafts.

\section{Discussion}

The mechanism of EGFR activation has been described as the ligand binding inducing the dimerization and activation of the cytoplasmic kinase domains, resulting in the phosphorylation of tyrosine residues in the $\mathrm{C}$-terminus and the subsequent recruitment of downstream effectors $(6,30)$. In addition, several reports have shown that EGFR can be activated without its ligand $(29,31,32)$. Cetuximab binds to the EGFR with a high affinity comparable to that of its ligands (34), and prevents ligand binding and receptor activation. Thus, the effects of cetuximab are restricted to cellular physiology regulated by ligand-dependent EGFR activation. Growth of SAS cells in monolayer cultures persists in serum-free medium and was inhibited by AG1478 treatment, but not by cetuximab treatment (Fig. 1). Wound repair by SAS cells was inhibited by cetuximab treatment (Fig. 2). These data show that dual systems of EGFR activation, including ligand-independent and ligand-dependent EGFR activation, play distinct roles in SAS monolayer cultures, in cell growth and in wound repair, respectively.

Cetuximab treatment reduced phosphorylation levels of EGFR and ERK in all cell lines examined, whereas phosphorylation of Akt was generally not affected by cetuximab treatment (Fig. 1). AG1478 treatment suppressed growth of SAS cells and the phosphorylation levels of ERK and Akt 
in monolayer culture conditions (Fig. 1). However, the PI3K inhibitor LY294002 and the Akt inhibitor MK2204 did not prevent SAS cell growth in a monolayer culture (Fig. 3). Taken together, these data suggest that the EGFR-ERK pathway may play a role in the growth of SAS cells in monolayer cultures In contrast, the phosphorylation levels of EGFR and Akt were upregulated in SAS aggregates (Fig. 3), growth of which is serum-dependent. Furthermore, growth was inhibited by cetuximab, AG1478, LY294002, and MK2206 (Figs. 3 and 4), indicating the growth of SAS aggregates was promoted by ligand-dependent EGFR activation through the PI3K-Akt pathway.

Anchorage-mediating structures on the extracellular matrix of epithelial cells serve a mechanical function and provide important survival signals to the cell. Detachment from the substrate, loss of cell anchorage, and concomitant loss of such survival signals leads to the induction of apoptosis, which is termed anoikis, in the majority of adherent cells (34-36). Acquisition of anoikis resistance of cancer cells constitutes an essential prerequisite for tumor progression and metastases in most cancers of epithelial origin $(37,38)$. In addition, anchorage-independent growth is a hallmark of cell transformation and is connected to elevated tumorigenic potential (39). Herein, we demonstrated that activation of the ligand-dependent EGFR/PI3K/Akt pathway, other than anoikis resistance, is necessary for anchorage-independent growth during metastasis, consistent with a recent report (40).

Lipid rafts, a plasma membrane subdomain, facilitate the organization of the specific molecular distribution and regulate the activity of receptors and proximal effectors of signaling (41). Our results demonstrated that the high levels of EGFR and Akt phosphorylation observed in suspension cultures of SAS cells were decreased when lipid rafts were disrupted with filipin III (Fig. 5). Thus, we speculate that lipid rafts serve as a platform in which EGFR and PI3K co-localize in the plasma membrane of SAS aggregates, thereby transmitting growth signals to the PI3K-Akt pathway through EGFR activation by ligand binding.

Cav1, a major component of caveolae and the cav1 scaffold in the plasma membrane subdomain (41), is involved in both tumor suppression and oncogenesis, depending on the tumor type and stage of progression $(42,43)$. Cav1 interacts with EGFR and negatively regulates EGFR activity (44). In the present study, Cav1 protein was detected in the cytoplasm of SAS aggregates by immunostaining (Fig. 5), indicating that Cav1 was not involved with EGFR activity in the plasma membrane of aggregated cells.

Wound repair of non-dividing SAS cells was markedly inhibited by cetuximab treatment (Fig. 2), suggesting that ligand-dependent EGFR activation is associated with migration of SAS cells in monolayers, as cell migration has been shown to be a fundamental step in wound repair (45-49). Tyrosine 14 phosphorylation of Cav1 regulates its interaction with integrins, various signaling adaptors, and protein tyrosine phosphatases (50). A galectin-3/phosphorylated Cav1/Rho A signaling module that mediates integrin signaling downstream of growth factor activation, leading to actin and matrix remodeling and tumor-cell migration in metastatic cancer cells (51). Thus, phosphorylated Cav1 may promote cell migration through EGFR activation in SAS monolayer cultures and de-phosphorylated Cav1 moves into the cytoplasm in SAS aggregates. We demonstrate the possibility that cetuximab inhibits metastasis and cell growth, because cell migration is essential for cancer metastasis.

Cetuximab treatment in combination with chemotherapy and radiotherapy has shown a survival benefit $(52,53)$. However, resistance to cetuximab caused by mutations in EGFR or downstream effectors have been reported (54-58). This study provides evidence that environmental stimuli alter the direction of EGFR signal transduction, resulting in a change in cetuximab sensitivity.

\section{Acknowledgements}

This manuscript has been edited for English language by Textcheck English consultants. Funding for this study was provided by Osaka University (M.N.) and Osaka Dental University (K.K.).

\section{References}

1. Siegel R, Naishadham D and Jemal A: Cancer statistics, 2012. CA Cancer J Clin 62: 10-29, 2012.

2. Cohen EE, Lingen MW and Vokes EE: The expanding role of systemic therapy in head and neck cancer. J Clin Oncol 22: 1743-1752, 2004.

3. Cooper JS, Pajak TF, Forastiere AA, Jacobs J, Campbell BH, Saxman SB, Kish JA, Kim HE, Cmelak AJ, Rotman M, et al; Radiation Therapy Oncology Group 9501/Intergroup: Postoperative concurrent radiotherapy and chemotherapy for high-risk squamous-cell carcinoma of the head and neck. N Engl J Med 350: 1937-1944, 2004.

4. Biscardi JS, Tice DA and Parsons SJ: c-Src, receptor tyrosine kinases, and human cancer. Adv Cancer Res 76: 61-119, 1999.

5. Abram CL and Courtneidge SA: Src family tyrosine kinases and growth factor signaling. Exp Cell Res 254: 1-13, 2000.

6. Schlessinger J: Cell signaling by receptor tyrosine kinases. Cell 103: 211-225, 2000.

7. Blume-Jensen $P$ and Hunter T: Oncogenic kinase signalling. Nature 411: 355-365, 2001.

8. Prenzel N, Fischer OM, Streit S, Hart S and Ullrich A: The epidermal growth factor receptor family as a central element for cellular signal transduction and diversification. Endocr Relat Cancer 8: 11-31, 2001.

9. Yarden Y and Sliwkowski MX: Untangling the ErbB signalling network. Nat Rev Mol Cell Biol 2: 127-137, 2001.

10. Marmor MD, Skaria KB and Yarden Y: Signal transduction and oncogenesis by ErbB/HER receptors. Int J Radiat Oncol Biol Phys 58: 903-913, 2004.

11. Nicholson RI, Gee JM and Harper ME: EGFR and cancer prognosis. Eur J Cancer 37 (Suppl 4): S9-S15, 2001.

12. Grandis JR and Tweardy DJ: Elevated levels of transforming growth factor $\alpha$ and epidermal growth factor receptor messenger RNA are early markers of carcinogenesis in head and neck cancer. Cancer Res 53: 3579-3584, 1993.

13. Rubin Grandis J, Melhem MF, Gooding WE, Day R, Holst VA, Wagener MM, Drenning SD and Tweardy DJ: Levels of TGF- $\alpha$ and EGFR protein in head and neck squamous cell carcinoma and patient survival. J Natl Cancer Inst 90: 824-832, 1998.

14. Ang KK, Berkey BA, Tu X, Zhang H-Z, Katz R, Hammond EH, Fu KK and Milas L: Impact of epidermal growth factor receptor expression on survival and pattern of relapse in patients with advanced head and neck carcinoma. Cancer Res 62: 7350-7356, 2002.

15. Galizia G, Lieto E, De Vita F, Orditura M, Castellano P, Troiani T, Imperatore V and Ciardiello F: Cetuximab, a chimeric human mouse anti-epidermal growth factor receptor monoclonal antibody, in the treatment of human colorectal cancer. Oncogene 26: 3654-3660, 2007.

16. Li S, Schmitz KR, Jeffrey PD, Wiltzius JJ, Kussie P and Ferguson KM: Structural basis for inhibition of the epidermal growth factor receptor by cetuximab. Cancer Cell 7: 301-311, 2005. 
17. Boeckx C, Baay M, Wouters A, Specenier P, Vermorken JB, Peeters $\mathrm{M}$ and Lardon F: Anti-epidermal growth factor receptor therapy in head and neck squamous cell carcinoma: Focus on potential molecular mechanisms of drug resistance. Oncologist 18: 850-864, 2013.

18. Rebucci M, Peixoto P, Dewitte A, Wattez N, De Nuncques MA, Rezvoy N, Vautravers-Dewas C, Buisine MP, Guerin E, Peyrat JP, et al: Mechanisms underlying resistance to cetuximab in the HNSCC cell line: Role of AKT inhibition in bypassing this resistance. Int J Oncol 38: 189-200, 2011.

19. Ohnishi Y, Minamino Y, Kakudo K and Nozaki M: Resistance of oral squamous cell carcinoma cells to cetuximab is associated with EGFR insensitivity and enhanced stem cell-like potency. Oncol Rep 32: 780-786, 2014.

20. Bakin AV, Rinehart C, Tomlinson AK and Arteaga CL: p38 mitogen-activated protein kinase is required for TGFbetamediated fibroblastic transdifferentiation and cell migration. J Cell Sci 115: 3193-3206, 2002.

21. Pal HC, Sharma S, Strickland LR, Agarwal J, Athar M,Elmets CA and Afaq F: Delphinidin reduces cell proliferation and induces apoptosis of non-small-cell lung cancer cells by targeting EGFR/ VEGFR2 signaling pathways. PLoS One 8: e77270, 2013.

22. MorozevichGE,Kozlova NI,Ushakova NA,Preobrazhenskaya ME and Berman AE: Integrin $\alpha 5 \beta 1$ simultaneously controls EGFRdependent proliferation and Akt-dependent pro-survival signaling in epidermoid carcinoma cells. Aging (Albany, NY) 4: 368-374, 2012.

23. Maa MC, Leu TH, McCarley DJ, Schatzman RC and Parsons SJ: Potentiation of epidermal growth factor receptor-mediated oncogenesis by c-Src: Implications for the etiology of multiple human cancers. Proc Natl Acad Sci USA 92: 6981-6985, 1995.

24. Simons K and Ikonen E: Functional rafts in cell membranes. Nature 387: 569-572, 1997

25. Wu W, Graves LM, Gill GN, Parsons SJ and Samet JM: Src-dependent phosphorylation of the epidermal growth factor receptor on tyrosine 845 is required for zinc-induced Ras activation. J Biol Chem 277: 24252-24257, 2002.

26. Bolard J: How do the polyene macrolide antibiotics affect the cellular membrane properties? Biochim Biophys Acta 864: 257-304, 1986.

27. Montesano R, Vassalli P and Orci L: Structural heterogeneity of endocytic membranes in macrophages as revealed by the cholesterol probe, filipin. J Cell Sci 51: 95-107, 1981.

28. Santos NC, Ter-Ovanesyan E, Zasadzinski JA, Prieto M and Castanho MA: Filipin-induced lesions in planar phospholipid bilayers imaged by atomic force microscopy. Biophys J 75: 1869-1873, 1998.

29. Zhang B, Peng F, Wu D, Ingram AJ, Gao B and Krepinsky JC: Caveolin-1 phosphorylation is required for stretch-induced EGFR and Akt activation in mesangial cells. Cell Signal 19: 1690-1700, 2007.

30. Hynes NE and Lane HA: ERBB receptors and cancer: The complexity of targeted inhibitors. Nat Rev Cancer 5: 341-354, 2005.

31. Shen $X$ and Kramer RH: Adhesion-mediated squamous cell carcinoma survival through ligand-independent activation of epidermal growth factor receptor. Am J Pathol 165: 1315-1329, 2004.

32. Lambert S, Vind-Kezunovic D, Karvinen S and Gniadecki R: Ligand-independent activation of the EGFR by lipid raft disruption. J Invest Dermatol 126: 954-962, 2006.

33. Goldstein NI, Prewett M, Zuklys K, Rockwell $P$ and Mendelsohn J: Biological efficacy of a chimeric antibody to the epidermal growth factor receptor in a human tumor xenograft model. Clin Cancer Res 1: 1311-1318, 1995.

34. Frisch SM and Francis H: Disruption of epithelial cell-matrix interactions induces apoptosis. J Cell Biol 124: 619-626, 1994.

35. Frisch SM, Vuori K, Ruoslahti E and Chan-Hui PY: Control of adhesion-dependent cell survival by focal adhesion kinase. J Cell Biol 134: 793-799, 1996.

36. Meredith JE Jr, Fazeli B and Schwartz MA: The extracellular matrix as a cell survival factor. Mol Biol Cell 4: 953-961, 1993.

37. Liu Z, Li H, Wu X, Yoo BH, Yan SR, Stadnyk AW, Sasazuki T, Shirasawa S, LaCasse EC, Korneluk RG, et al: Detachmentinduced upregulation of XIAP and cIAP2 delays anoikis of intestinal epithelial cells. Oncogene 25: 7680-7690, 2006.

38. Rosen K, Coll ML, Li A and Filmus J: Transforming growth factor-alpha prevents detachment-induced inhibition of $\mathrm{c}-\mathrm{Src}$ kinase activity, Bcl-XL down-regulation, and apoptosis of intestinal epithelial cells. J Biol Chem 276: 37273-37279, 2001.
39. Hanahan D and Weinberg RA: Hallmarks of cancer: The next generation. Cell 144: 646-674, 2011.

40. Liu P, Begley M, Michowski W, Inuzuka H, Ginzberg M, Gao D, Tsou P, Gan W, Papa A, Kim BM, et al: Cell-cycle-regulated activation of Akt kinase by phosphorylation at its carboxyl terminus. Nature 508: 541-545, 2014.

41. Lajoie P, Goetz JG, Dennis JW and Nabi IR: Lattices, rafts, and scaffolds: Domain regulation of receptor signaling at the plasma membrane. J Cell Biol 185: 381-385, 2009.

42. Williams TM, Hassan GS, Li J, Cohen AW, Medina F, Frank PG, Pestell RG, Di Vizio D, Loda M and Lisanti MP: Caveolin-1 promotes tumor progression in an autochthonous mouse model of prostate cancer: Genetic ablation of Cav-1 delays advanced prostate tumor development in tramp mice. J Biol Chem 280: 25134-25145, 2005.

43. Quann K, Gonzales DM, Mercier I, Wang C, Sotgia F, Pestell RG, Lisanti MP and Jasmin JF: Caveolin-1 is a negative regulator of tumor growth in glioblastoma and modulates chemosensitivity to temozolomide. Cell Cycle 12: 1510-1520, 2013.

44. Couet J, Sargiacomo M and Lisanti MP: Interaction of a receptor tyrosine kinase, EGF-R, with caveolins. Caveolin binding negatively regulates tyrosine and serine/threonine kinase activities. J Biol Chem 272: 30429-30438, 1997.

45. Blay J and Brown KD: Epidermal growth factor promotes the chemotactic migration of cultured rat intestinal epithelial cells. J Cell Physiol 124: 107-112, 1985.

46. Chen JD, Kim JP, Zhang K, Sarret Y, Wynn KC, Kramer RH and Woodley DT: Epidermal growth factor (EGF) promotes human keratinocyte locomotion on collagen by increasing the alpha 2 integrin subunit. Exp Cell Res 209: 216-223, 1993.

47. Fujii K, Dousaka-Nakajima N and Imamura S: Epidermal growth factor enhancement of HSC-1 human cutaneous squamous carcinoma cell adhesion and migration on type I collagen involves selective up-regulation of alpha 2 beta 1 integrin expression. Exp Cell Res 216: 261-272, 1995.

48. Matthay MA, Thiery JP, Lafont F, Stampfer F and Boyer B: Transient effect of epidermal growth factor on the motility of an immortalized mammary epithelial cell line. J Cell Sci 106: 869-878, 1993.

49. Basson MD, Modlin IM and Madri JA: Human enterocyte (Caco-2) migration is modulated in vitro by extracellular matrix composition and epidermal growth factor. J Clin Invest 90: 15-23, 1992.

50. Goetz JG, Lajoie P, Wiseman SM and Nabi IR: Caveolin-1 in tumor progression: The good, the bad and the ugly. Cancer Metastasis Rev 27: 715-735, 2008.

51. Boscher C and Nabi IR: Galectin-3- and phospho-caveolin1-dependent outside-in integrin signaling mediates the EGF motogenic response in mammary cancer cells. Mol Biol Cell 24: 2134-2145, 2013.

52. Vermorken JB, Mesia R, Rivera F, Remenar E, Kawecki A, Rottey S, Erfan J, Zabolotnyy D, Kienzer HR, Cupissol D, et al: Platinum-based chemotherapy plus cetuximab in head and neck cancer. N Engl J Med 359: 1116-1127, 2008.

53. Bonner JA, Harari PM, Giralt J, Azarnia N, Shin DM, Cohen RB, Jones CU, Sur R, Raben D, Jassem J, et al: Radiotherapy plus cetuximab for squamous-cell carcinoma of the head and neck. N Engl J Med 354: 567-578, 2006.

54. Sartore-Bianchi A, Martini M, Molinari F, Veronese S, Nichelatti M, Artale S, Di Nicolantonio F, Saletti P, De Dosso S, Mazzucchelli L, et al: PIK3CA mutations in colorectal cancer are associated with clinical resistance to EGFR-targeted monoclonal antibodies. Cancer Res 69: 1851-1857, 2009.

55. Sartore-Bianchi A, Di Nicolantonio F, Nichelatti M, Molinari F, De Dosso S, Saletti P, Martini M, Cipani T, Marrapese G, Mazzucchelli L, et al: Multi-determinants analysis of molecular alterations for predicting clinical benefit to EGFR-targeted monoclonal antibodies in colorectal cancer. PLoS One 4: e7287, 2009.

56. Laurent-Puig P, Lievre A and Blons H: Mutations and response to epidermal growth factor receptor inhibitors. Clin Cancer Res 15: 1133-1139, 2009.

57. De Rock W, Lambrechts D and Tejpar S: K-ras mutations and cetuximab in colorectal cancer. N Engl J Med 360: 834, 2009.

58. De Roock W, Claes B, Bernasconi D, De Schutter J, Biesmans B, Fountzilas G, Kalogeras KT, Kotoula V, Papamichael D, LaurentPuig P, et al: Effects of KRAS, BRAF, NRAS, and PIK3CA mutations on the efficacy of cetuximab plus chemotherapy in chemotherapy-refractory metastatic colorectal cancer: A retrospective consortium analysis. Lancet Oncol 11: 753-762, 2010. 